\title{
The Impact of Electronic Words of Mouth (eWOM) to the Brand Determination of Higher Education in Malaysia: From the Perspective of Middle East's Student
}

\author{
Azizul Halim Yahya, A Aziz Azizam* and Dzulkarnain Bin Mazlan \\ Faculty of Communication \& Media Studies, UiTM, Malaysia
}

\begin{abstract}
Electronic word-of-mouth (eWOM) refers to the knowledge exchange between people in the online sphere. Most studies on eWOM focuses on product and services, subsequently, the exchange of knowledge has a direct relationship on brand determination. Therefore, this affects the overall value of the organization. The purpose of this paper is to examine the brand determination of Higher Education in Malaysia from the perspectives of Middle Eastern students in Malaysia. A semi-structured focus group was conducted among Middle Eastern students studying in various public and private tertiary institutions in Malaysia. The thematic analysis was generated by using qualitative data management in order to enhance the rigorousness of the findings. Consequently, the key indicator for this study is the value of information from eWOM that effects the brand determination. Good brand value is an important tool in enhancing awareness as well as altering or reinforcing stereotypical views. The results of this study have brought out several aspects of brand determination of Higher Education in Malaysia like cross-culture experience, policy and finance.
\end{abstract}

Keywords: Electronic word-of-mouth (eWOM); Branding; Higher education

\section{Introduction}

The advancement of the new media has created a whole new concept of communication. Today, the internet is one of the most important communication tool and one's ability of accessibility and utilization of it is compulsory as the internet has become a platform for people to express their feelings, thoughts, experiences, share information and etc. The existence of Web 2.0 has extended the conventional mode of communication ability to an unimaginable state and will continue to dynamically improve and advance communication abilities. The statement is called electronic word-of-mouth (eWOM). Many studies have been done in other countries regarding eWOM and its effects toward product and services. A study done by Peter and Olsen [1], mentioned that the power to influencing consumer-decision making is determined by word-of-mouth (WOM), a non-commercial marketing medium. The audiences or consumers will not only seek information given by the marketers and producers, but they will also their friends, acquaintance, or even other consumers as information references [2]. eWOM refers to the knowledge exchange between people in the online sphere. Therefore, the exchange of knowledge has a direct relationship on brand determination affecting the overall value of the organization, especially higher education. Tertiary education institutions in Malaysia plays an important role in realization of the country's Vision 2020; and they have realized a need to develop sustainable strategies in balancing quality, first-class thinking, well-balanced, well-adjusted, united, innovative intellectuals to have a high income economy as a response to the current complex and highly competitive marketplace. In preparation for Vision 2020 an effective strategy of turning branding as a solution should be taken into consideration. The brand is an intangible asset for each organization [3]. This paper aims to present the impact of eWOM towards brand determination of Higher Education from the perspectives of Middle Eastern students who are currently studying in Malaysia. The driven objectives of this paper are to explore the key determinant of brand credibility of Higher Education in Malaysia through eWOM and to investigate any opportunity in improving the brand credibility of Higher Education in Malaysia.

\section{Literature Review}

\section{eWOM}

The advancement of new technologies creates a new unique platform for communication. The definition of electronic word-ofmouth (eWOM) communication is referred to the statements made by potential, actual, and former buyers. The statements regarding the products, services, or company via the internet can be both positive and negative [4] as a result of the continuous enhancement of new technologies, replacing Web 1.0 with Web 2.0 at the $y$ end of year 2004. Web 2.0 gears (e.g. social network, forum, web blog, etc.) allow people to not only read but inscribe too. It helps the user to easily utilize (read, listen, watch, download, search, and buy), create (personalize, aggregate, and contribute), share (publish and upload), facilitate (tag and recommend), and communicate (send messages, post comments, rate, and chat) online. These activities allow the audiences to share their thoughts without boundaries and provide a platform for actual exchange of information with regards to the product [5]. Studies in various fields have shown that the most influential agent in communication is word of mouth. Gabriel Tarde defined that the strongest agent of imitation, propaganda of sentiments, ideas, and mode of actions are conversations. These reports validate the most powerful mechanism to persuade is word of mouth. It can influence people in many ways and its influencing power is limitless. Among its power is

*Corresponding author: A Aziz Azizam, Faculty of Communication \& Media Studies, UiTM, Malaysia, Tel: 013-4333584/014-7577807; E-mail: abdulazizazizam@yahoo.com

Received November 23, 2013; Accepted February 13, 2014; Published February 20, 2014

Citation: Yahya AH, Azizam AA, Mazlan DB (2014) The Impact of Electronic Words of Mouth (eWOM) to the Brand Determination of Higher Education in Malaysia: From the Perspective of Middle East's Student. J Mass Communicat Journalism 4: 181. doi:10.4172/2165-7912.1000181

Copyright: @ 2014 Yahya $\mathrm{AH}$, et al. This is an open-access article distributed under the terms of the Creative Commons Attribution License, which permits unrestricted use, distribution, and reproduction in any medium, provided the original author and source are credited. 
the ability to influence the purchase of household and food products and many more. Some scholars believe that word-of-mouth (WOM) is more effective than any other conventional promotion tools such as newspaper, radio, and magazine advertising and personal selling [2], thus, making WOM as a powerful communication mechanism. Parallel to the evolving world, new media technologies create improved versions of electronic word-of-mouth (eWOM). Because it is located in the internet, eWOM is a new powerful platform for communication information and knowledge. The whole world may now share and gain information regardless of physical geographical locations. The current buzz agent in marketing is eWOM and with this, advertising expenditure may be reduced.Its existence becomes the reliable source of reference for certain products or services in the eyes of its audience. Several studies state that the strong connection between eWom and sales. The positive response on eWOM regarding certain products is reflected by the increasing sales of the product involved. The source of eWOM determines the direct and positive relationship between message source credibility and brand trust, brand affection, purchase intention, and brand attitude concerning services and product too [3]. From the literature we can inference the significant impact eWOM could bring towards the brand of Higher Education in Malaysia.

\section{Branding higher education}

For decades, many scholars have studied various areas of the brand and it differs from one another according to its nature. Kotler [6] defined it as, "the name associated with one or more items in the product line, which is used to identify the source of character of the item(s)". In the field of marketing research and practice, the number of research regarding branding is increasing its attention to the processes associated with building a strong relationship between brand and consumer, and it is often argued that the brand is the most valuable asset for any company [7]. In determining the preference of the audience or consumer, the concept of brand equity is of particular relevance to indicate consumer choice. In the struggle with the changing and highly competitive marketplace, universities and colleges have turned to branding as a solution in dealing with today's global challenges. The Higher Education organizations have their own unique characteristics, subsequently the challenges in terms of marketing also differs from other organizations. According to Andreassen and Streukens [8], customers' voluntary contribution in virtual communities may add to brand and customer equity. This inferences eWOM and brand are highly interrelated in this present world. The marketers in the area of Higher Education services should realize that developing a positive brand image is more important than creating awareness. The investment towards creating and maintaining the determinants of the brand image dimension of brand equity should be the focus rather than simply expanding their promotional campaigns [9]. This is crucial in having an extremely well planned marketing strategy in Higher Education. The objectives of this research are to explore the perspectives from the Middle Eastern students studying in Malaysia and to understand how they determine Higher Education from eWOM.

\section{Methodology}

In this research the researcher explores the concept of brand determination of Higher Education in Malaysia from the perspectives of Middle Eastern students through eWOM and the quest of understanding the function of eWOM towards the development of the brand determination of Higher Education in Malaysia has been embarked. The researcher uses the qualitative method of studying a semi-structured focus group as the main advantage of the focus group is the purposeful and meaningful use of interaction and communication between the respondents to generate the required data, where the purpose of it is to collect in-depth information from a group of people which represents the population of interest. This technique when carried out gives a wealth of required data and needed information. From the acquired data, the researcher has identified the theme which supports the objectives of this research.

\section{Participants}

For the semi-structured focus group, six (6) informants (consisting of three (3) males and three (s) females) of various levels of education, political, and geographical background were selected by the referral sampling technique. This is done in order to obtain maximum understanding of brand determination of Higher Education in Malaysia.

\section{Materials and Procedure}

In order to ensure validity of the research, it is important that the understanding of participants pertaining the subject is discussed at the beginning of the session. To ensure the understanding of the informants regarding the subject the researcher demonstrated and explained the definition of electronic word-of-mouth (eWOM) to the audience in a concise and clear manner. The Four Basic Steps of collecting qualitative data was applied in accordance to the suggestion of Morgan [10,11]. These Four Basic Steps are planning, recruiting, moderating, and analyzing and reporting.

\section{Planning}

Clarify the research and determine interview questions that need to be asked during the focus group. All interview questions will cover the research question. A set of interview questions were prepared for participants in the focus group session. During this stage, the researcher also prepares the venue, all supporting materials and electronic devices that will be needed during the semi-structured focus group.

\section{Recruiting}

Selecting and managing respondents appropriately will ensure good return from them $[10,11]$. The participants for this research will be selected using referrals techniques allowing the researcher to reach one person who produces another several names [10,11] (Table 1).

\section{Moderating}

For the focus group, a sound moderator will be appointed to take charge in guiding the discussion and to listen to what the group members have to say but does not participate, share views, engage in discussion, or shape the outcome of the group interview [12-14]. According to Basch, the role of a moderator is to generate a nonthreatening supportive climate that encourages the entire respondent to share views, interjecting probing comment(s), transition questions, and cover the entire key question. He or she will devote time to deliberate and clarify the definition of the topic and refine the terms.

\begin{tabular}{|l|l|l|l|}
\hline No & Informants Origin & Gender & Level of Study \\
\hline 1 & Jordan & Female & Degree \\
\hline 2 & Yemen & Female & PhD \\
\hline 3 & UAE & Female & Degree \\
\hline 4 & Iran & Male & PhD \\
\hline 5 & Kuwait & Male & PhD \\
\hline 6 & Palestine & Male & Masters \\
\hline
\end{tabular}

Table 1: Participants in Focus group. 
The understanding of the informants towards the subject is important to ensure the data stands correct.

\section{Analyzing and reporting}

The data collected will be transcribed later and will be analyzed using thematic analysis. Thematic analysis allows the researcher to explore the pattern and the main idea of the collected data. It is also a method used for "identifying, analyzing, and reporting patterns (themes) within data".

\section{Findings and Discussions}

The efficient focus group has provided an extensive in-depth data from various angles of understanding regarding eWOM and the impacts to the brand determination towards Higher Education in Malaysia from the perspectives of Middle-Eastern students. Data was organized and analyzed using NVIVO 8 , a data management software. The impact service quality had on eWOM was examined with Middle Eastern students' satisfaction and commitment being modeled as mediators of this relationship. The results suggested functional service quality rather than technical service quality that impactse WOM formation, with students' satisfaction playing an important mediating role. The research also showed that although student satisfaction had a significant effect on both aspects of commitment (affective commitment and high-sacrifice commitment), affective commitment led to given eWOM. Nodes and developed themes were derived from the extensive data. Several important elements transformed into keys of brand determination of Higher Education in Malaysia from eWOM; they are infrastructure excellence, social and political environment stability, and good service and hospitality (Figure 1).

All informants gave positive response to the three keys from eWOM. These keys of brand determination are in correlation in terms of generating eWOM formation in the social network conversation. Middle Eastern students saw the advancement of infrastructure provided in Malaysia is one of the major factors influencing credibility measurement of Higher Education branding. Another main contributor is the social and political environment which consists of healthy democracy admired by participants, a stark contrast compared to their own countries. Political stability provides a civilized social life and good service and hospitality for the Middle Eastern students. The efficiency of service and hospitality becomes a major factor in eWOM formation determining the Higher Education branding of Malaysia. The Middle Eastern students were satisfied with the cordial services and hospitality provided by the Malaysian government. Important intervening factors that enable opportunities for Malaysian Higher Education are identified.It was suggested by the focus group's participants that admission policy for international students should be opened wider for undergraduate studies as the opportunity to study in Malaysia is genuinely meaningful to them, therefore, the experience and opportunity should be extended to more Middle Eastern students.

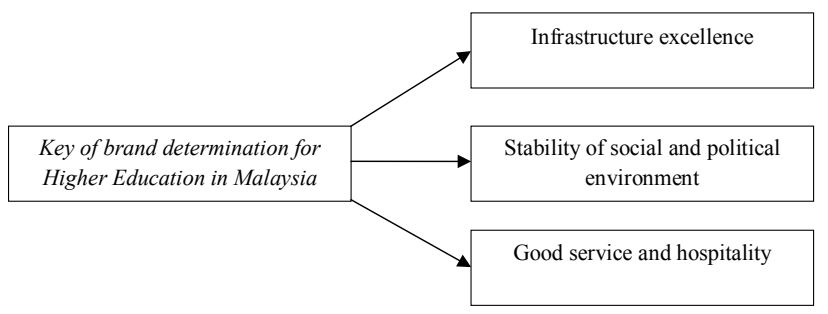

Figure 1: Main themes from the focus group findings.

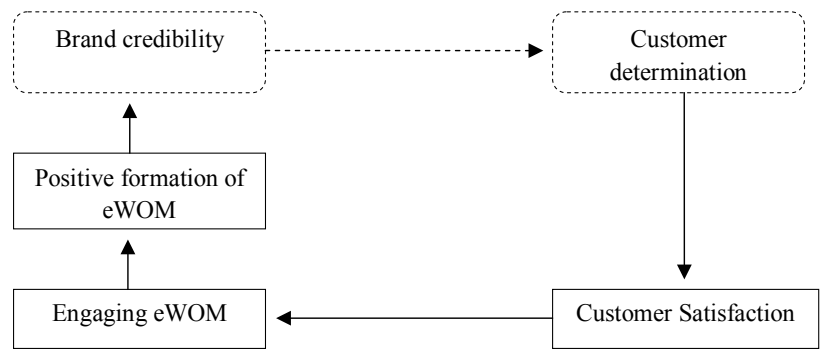

Figure 2: Model the impact of eWOM to the brand determination; from the perspectives of Middle East's student.

Another factor that catalyst positive response is the cross-culture experience gained studying in Malaysia. The findings suggested that the university should provide local adoptive family orientation programs for the international students. This program would benefit the foreign students on the basis of a purposeful and useful relationship between foreign students and local family. Difficulties for foreign students especially Middle Easterners to adapt to local culture were brought forward. The findings also suggested that Higher Education in Malaysia should provide more efficient customer service which will operate online for 24 hours everyday for international students to refer to, regarding any problem that they encountered or might encounter. Another important contributing factor is financial support. From the findings, financial assistance is crucial for international students especially Middle Eastern students as the difference in currency puts pressure for the students to survive. Financial support may not specifically be in the form of scholarship, it could be by creating and allowing students to work in tertiary institutions. This suggestion could be a preventative measure for international students to avoid getting into unhealthy money generating activities such as vice, prostitution, drugs or/and others. The research also examined adult learners enrolled in undergraduate programs. While the younger and full-time students may not be impacted by eWOM in the same way like the adult students, practical implications of having a better understanding of eWOM formation helps Higher Education institution managers focus on the "right" antecedents; which are functional service quality, satisfaction, and affective commitment.

The results also suggest broader responsibilities for such managers. If the goal is to increase student enrolments, the management of student services is crucial and it should be seen as a marketing tool, as well as an administrative process. Originality/value: The relationships examined have not been investigated previously in an educational environment and the results suggest education managers need to understand them as they play a crucial role in determining eWOM. eWOM plays a significant role in determining brand for students' educational preferences. If processes and strategies that improve service quality, satisfaction, and commitment can be developed, eWOM will naturally be positively influenced.

One of the ways to attract enrollments of new students is by creating brand credibility. The velocity it bears would attract prospective customers, resulting into customers of the particular brand. Tertiary institutions that satisfy the customers' needs, wants, and desires would morph them into loyal customers of the products and services being offered. Satisfied and loyal customers in return would do some advertising by their wording of a particular brand for companies that would otherwise require the universities and colleges to invest a tremendous amount of money. Higher learning institutions should take 
Citation: Yahya AH, Azizam AA, Mazlan DB (2014) The Impact of Electronic Words of Mouth (eWOM) to the Brand Determination of Higher Education in Malaysia: From the Perspective of Middle East's Student. J Mass Communicat Journalism 4: 181. doi:10.4172/2165-7912.1000181

Page 4 of 4

advantage of the eWOM that their customers would bring and churn profit for them (Figure 2).

This research investigates the above-mentioned relationships in one model. Firstly, the effects of brand credibility of companies on customer loyalty were explored. The results and findings obtained substantiated that there is a positive relationship between brand credibility and customer satisfaction and loyalty. On the other hand, this study found that customers' satisfaction and loyalty are positively related to eWOM. This is the first research done in Malaysian context that examines the effect of brand determination on eWOM with references to Malaysian universities. It is visible through this research that the concept of brand credibility is an important factor for Higher Education in Malaysia and relatively important for other service providers too. The prominent relationship between brand credibility and customers' satisfaction and loyalty found the relationship between brand credibility and customers' loyalty showed to be more significant. This finding indicates that the greater the brand credibility is for a particular brand, the higher the customers' determination. On the other hand, in the second part of model, the relationship between customers' satisfaction and eWOM found to be more significant than the relationship between customers loyalty and eWOM, which indicates that the greater the customers' satisfaction, the greater the chances that they engage in the eWOM activities.

\section{Recommendation}

Based on the above discussion, it can be argued that the brand determination influences word of mouth through students' satisfaction. Students' satisfaction has shown to be more influential on word of mouth. By having satisfied students, higher education institutions are able to benefit from eWOM. Higher education in Malaysia should pay more attention to students' satisfaction and keep them consistently satisfied with their services. This is due to the fact that students' satisfaction would impact greatly on word of mouth. It is considered to be one of the most cost effective and easiest ways in attracting new students' enrollment instead of spending a tremendous amount of unnecessary money on other media source in terms of creating brand awareness.

\section{References}

1. Peter JP, Olson JC (2002) Consumer Behavior and Marketing Strategy. Sixth Edition. Irwin, McGraw-Hill.

2. Herr PM, Kardes FR, Kim J (1991) Effects of word-of-mouth and productattribute information on persuasion: an accessibility-diagnosticity perspective. Journal of Consumer Research 17: 454-462.

3. Temporal, Paul (2004) Public Sector Branding Asia.Times Edition Singapore.

4. Thorsten Hennig-Thurau KPG, Gianfranco W, Dwayne DG (2004) Electronic Word-Of-Mouth Via Consumer-Opinion Platforms: What Motivates Consumers To Articulate Themselves On The Internet? Journal of Interactive Marketing 18: 38-52.

5. Park DH, Lee J, Han I (2007) The Effect of On-Line Consumer Reviews on Consumer Purchasing Intention: The Moderating Role of Involvement. International Journal of Electronic Commerce 11: 125-148.

6. Kotler, Philip (2000) Marketing Management. The Millennium Edition. Upper Saddle River, Prentice Hall.

7. Aaker D (2003) The power of the branded differentiator. MIT Sloan Management Review 45: 83-87.

8. Andreassen TW, Streukens S (2009) Service innovation and electronic wordof-mouth: is it worth listening to? Managing Service Quality 19: 249-265.

9. Maha M, Christine E, Wael K (2010) Brand equity in higher education. Managing Service Quality 19: 3.

10. Morgan DL (1998a)The Focus Group Guidebook. Sage, United States of America.

11. Morgan DL (1998b) Planning For Focus Group. Sage, United States of America.

12. Krueger RA (1998a) Analyzing \& Reporting Focus Group Result. Sage, United States of America.

13. Krueger RA (1998b) Developing Question for Focus Group. Sage, United States of America.

14. Krueger RA (1998c) Moderating Focus Group. Sage, United States of America. 